\title{
Aircraft Ground Handling: Analysis for Automation
}

\author{
Diego Alonso Tabares ${ }^{1}$ \\ Airbus, Blagnac, 31707, France \\ Félix Mora-Camino ${ }^{2}$ \\ ENAC, Toulouse, 31055, France
}

\begin{abstract}
This paper presents the state of the art of aircraft ground handling at airports. The main opportunities for automation of these activities are pointed out. This leads to identify different challenges to be overcomed to build safe and efficient automated ground handling operations. Greatest opportunity for automation lies with automated docking of ground support equipment to aircraft in the short term, with further autonomous vehicles moving around the aircraft and automated systems within the aircraft later on.
\end{abstract}

\section{Introduction}

$\mathrm{T}$ HE ground handling operations represent the airside activities at airports in charge of processing passengers, cargo, facilities and supplies at and around parked aircraft. Most of these operations are performed by different service providers, using vehicles as Ground Support Equipment (GSE) which is specific to each type of operation.

Ground handling is not considered a prominent activity within the Air Transportation System (ATS), however this activity is an important enabler for efficient airport operation and its management is an important issue. Over the last decades, the complexity of ATS has increased to cope with the worldwide growth of air traffic. Today the operation of this system involves global actors (airports, airlines, Air Traffic Control (ATC), Air Traffic Management (ATM)) as well as local actors (ground handlers, local suppliers...) whose coordination, while pursuing different and sometimes contradictory objectives, is difficult to achieve.

\section{Aircraft Ground Handling State of the Art}

In this paper, only the aircraft ramp handling activities will be considered: those that are in direct interface with the aircraft and are done at the airport ramp. Excluded are those activities like passenger check-in done physically elsewhere or seasonal handling activities like aircraft de-icing. The scope of this paper covers all civil passenger aircraft of more than one hundred seats still in production. The Airbus A330-200 aircraft is used in the figures for illustration purposes along this paper.

The ground handling tasks are usually defined and contracted using a Service Level Agreement (SLA) that defines the scope, price and quality level desired and Key Performance Indicators (KPI) as well. Most of the industry use the IATA AHM 810 Standard Ground Handling Agreement ${ }^{1}$ as a template. From overall ground handling operation KPI, the ones that are considered the most important are:

- On time performance (OTP).

- Minimize the number of resources (GSE, operators, infrastructure) needed.

- The predictability for ATM in general and Aircraft Collaborative Decision Making $\left(\mathrm{ACDM}^{2}\right)$ milestones in particular.

- Aircraft ramp damage avoidance.

- Avoid personnel incidents and accidents.

It is to be noted that some of the KPI are pushing in different directions e.g. minimize resources while respecting OTP.

\footnotetext{
${ }^{1}$ Senior Engineer, Airport Operations, 1 Rond-Point Maurice Bellonte and AIAA Member.

${ }^{2}$ Professor, ENAC laboratory, 7 Avenue Edouard Belin and AIAA Member.
} 
The ground handling activities are usually divided in (See Figure 1):

- "Over the wing" activities, meaning aircraft passenger cabin related activities: passenger boarding and deplaning, catering galleys, cabin cleaning and preparation, safety and security checks as needed.

- "Under the wing" activities, which are cargo (both containerised and bulk) unloading and loading and other ramp activities: provide electricity (Ground Power Unit (GPU)), condition aircraft cabin temperature (PreConditioned Air unit (PCA)), chocking of landing gears, use of cones, marshalling, refuelling, potable water and toilet servicing, towing/pushback and provide access means to the passengers (via stairs, ramps or Passenger Boarding Bridge (PBB) )

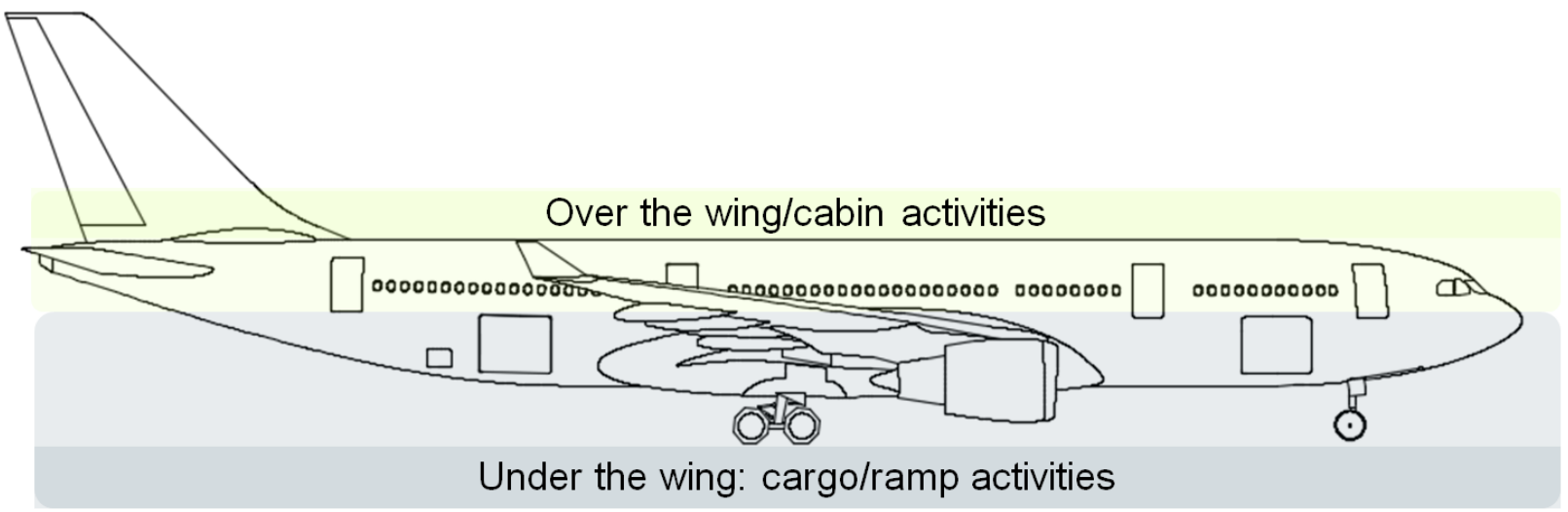

Figure 1: Aircraft typical starboard view. Source: Airbus, authors

Each activity, unless specified differently, comprises the phases of GSE docking or supply connection to the aircraft, the task itself and the GSE removal or disconnection of the utility. Each activity requires a specific GSE, with its own design, shape and constraints (See Figure 3). The GSE typology varies wildly: can be towed by hand, towable or be self-propelled. Many GSE like cargo loaders, PBB and towbarless tractors, are designed for use at the airport only. Other GSE like catering trucks, de-icers, potable/lavatory trucks are adapted from existing automotive chassis suppliers.

The generic sequence of these activities, shown in Figure 2, is established depending on:

- Those tasks related to aircraft arrival: passenger deplaning, cargo unloading, toilet servicing, removal of catering, cabin cleaning.

- Tasks related to aircraft departure: passenger boarding, cargo loading, refuelling, potable water, provide catering, cabin preparation.

- Safety and security requirements for the overall operation.

- Aircraft accessibility to doors and servicing panels. If the aircraft doors and servicing panels arrangement have been designed correctly, most, if not all, of the activities could be done in parallel (See Figure 3). But with some aircraft this is not possible as the operation of one door blocks the access to other door or servicing panel.

- Links and constraints (represented with arrows in Figure 2). These constraints can be hard or soft.

- Examples of hard constraints are:

- Need to unload the cargo before loading it

- Need to deplane passengers before you enplane them.

- Operational constraints: e.g. some aircraft to avoid tail tipping need to have unloaded first their aft cargo compartment and load first their forward cargo compartment.

- Examples of soft constraints, which will be highly depending on time pressure (degraded standards as risk mitigation) and operator policies, are:

- Catering start in some galleys while passengers deplaning has not yet finished.

- Some ground operators start approaching the PBB even with the aircraft not fully onchocks.

As a result, the aircraft ramp handling sequence is composed of mostly independent chains of tasks for current aircraft from the moment the aircraft is "on-chocks", namely: 
○ Passenger cabin related: passenger deplaning, cabin activities (catering and cleaning) and passenger boarding

- Cargo and bulk unloading/loading

- Refuelling. (For many years it is widely accepted to have refuelling with passenger onboard the aircraft. Some operational rules may apply like number of available exits for passenger egress and firefighters and passengers informed, also unimpeded route for the refuelling vehicle to exit. Defacto, this makes refuelling independent from any other activity in the turnaround. This will be the assumption taken during this paper. Please note that there are occasions in real operations where this is not true, for example with long refuel trucks that will prevent cargo loaders and catering truck access to aircraft doors).

- Potable water servicing

- Toilet servicing

- Ground power and air conditioned supply (depending on pilot request, availability and regulations of use for aircraft APU (Auxiliary Power Unit))

\section{Aircraft ramp handling - typical turnaround time}

Over the wing/cabin activities

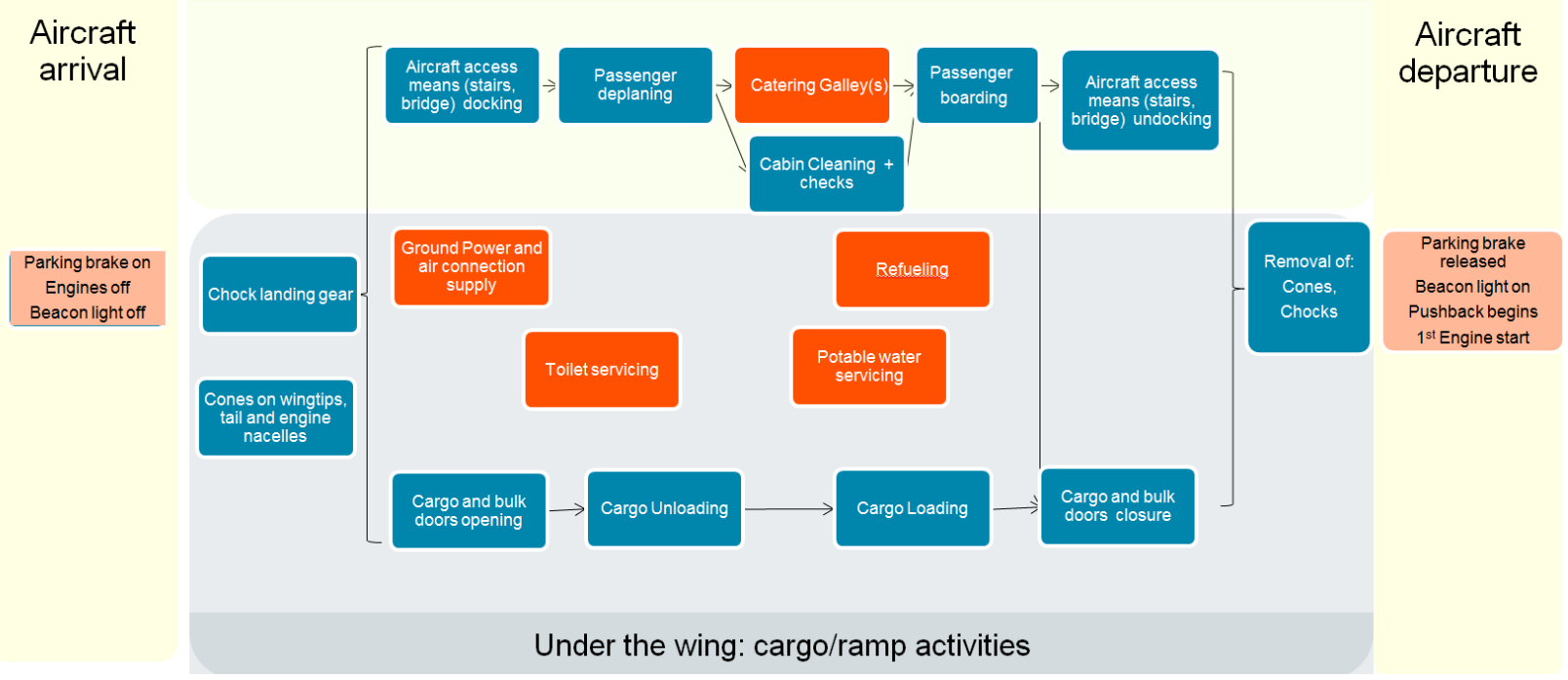

Figure 2: Typical turnaround time - tasks sequence. Source: authors

It is worth to be noted that not all of these activities are carried out at each aircraft stop. First and last flight of the day will do only the tasks related to departure and arrival respectively. For the flights in between, some tasks may or may not be done depending on aircraft status, next mission and infrastructure available at the airport (in Figure 2 these optional tasks are shown in orange).

The TurnaRoundTime (TRT) can be defined as the time between the aircraft is on-chocks until it is off-chocks. It can be estimated following a scenario and some assumptions and a set of parameters and rates. The reader is invited to review the different airframe manufacturer's assumptions in their aircraft characteristics or airport planning manuals ${ }^{3}$. An example of TRT result for a given scenario is presented in Figure 4 . The vast majority of the cases, the critical path, the sequence of activities that will determine the duration of TurnaRoundTime (TRT), is given by the cabin related activities chain (passenger deplaning, catering, cleaning, cabin preparation and checks and passenger boarding).

It is important to highlight that even for the same aircraft type, the turnaround time is not a fix value and the schedule and the duration of each task and in consequence of the global TRT will vary, because it also depends on:

- Aircraft cabin layout (number of seats and classes), mission (short vs longer sector), load factor, specificities of some flight/destinations (e.g. some destination have higher baggage loads). 
- Airline operation, schedule and slots available (feeder \& hub operation at homebase or destination, transit; point-to-point operation).

- Ramp layout (aircraft handled at the gate with fix facilities vs at a remote stand with no fix equipment...),

- Infrastructure related: e.g. availability and number of PBB

- Airline and ground handling policy and procedures. E.g. pre-boarding passengers at the terminal as most European low cost airlines do. "H-40 mins" (being H, the flight departure time) boarding policy for long range aircraft, "H-30 boarding" for short haul aircraft.

- Resources: human (number, qualifications, efficiency) and GSE equipment (number, type and status and availability).

- Ground handler efficiency

- Environment: weather (wind, rain, ice, high/low temperatures) and visibility (dust, fog, night)

In addition, there are several providers in charge of handling activities for the same aircraft turnaround. Depending on airport size and market regulations (see for example European ground handling directive ${ }^{4}$ ), the ground handling companies that can typically be found for the same aircraft turnaround are:

- One specialised refuelling company

- One specialised catering company

- At least one company dealing with ramp handling activities (could be even more than four)

- One company (usually also dealing with some aspects of ramp handling) dealing with passenger handling.

To complete the list of actors for ground handling, it should be added the airline, the ATC, the airport, the cockpit crew, the cabin crew and the ground handling crew (from five to dozens). This high number of actors involved adds to the complexity and management of the process.

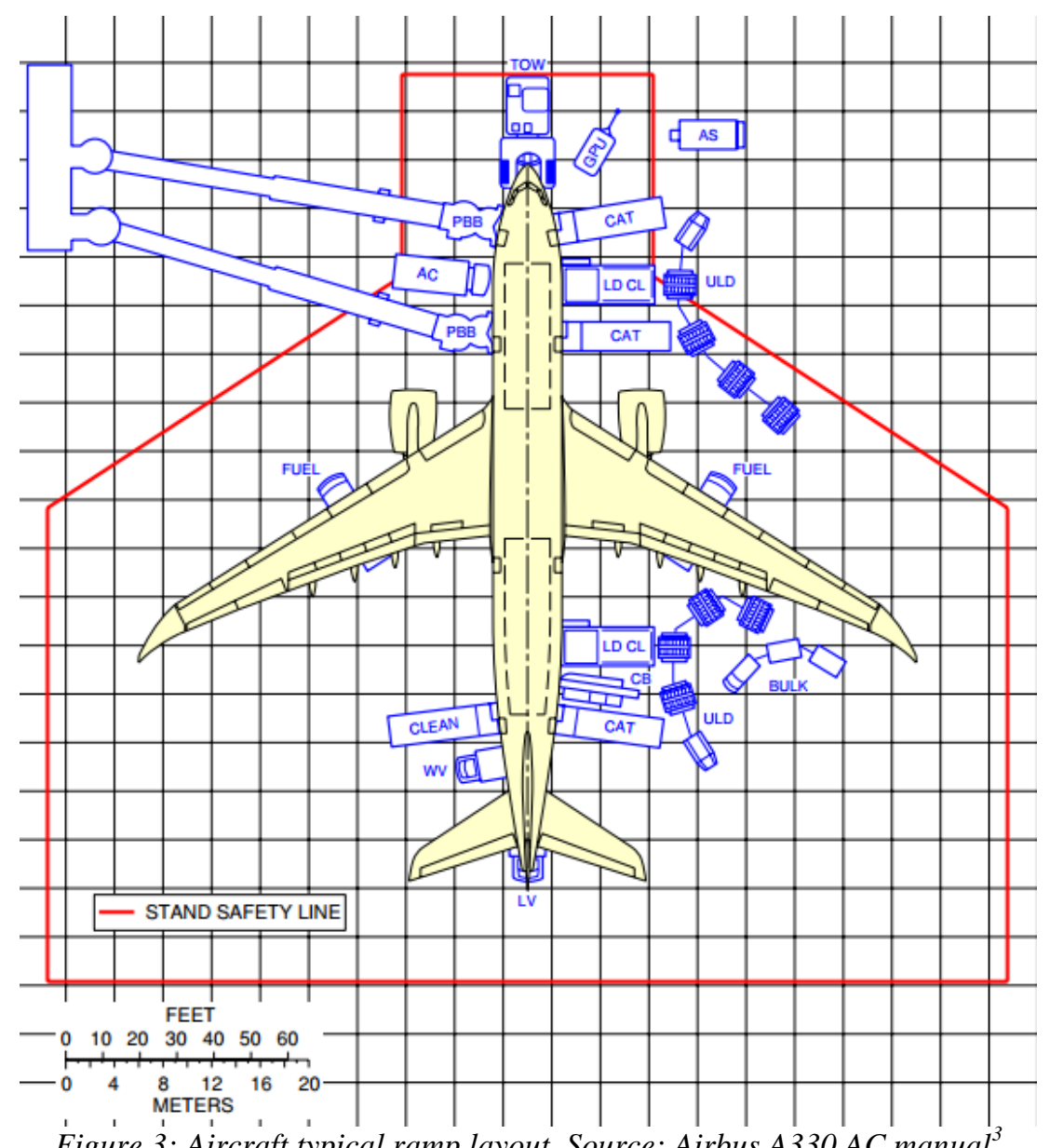

Figure 3: Aircraft typical ramp layout. Source: Airbus A330 AC manual ${ }^{3}$

4

American Institute of Aeronautics and Astronautics 
TRT: $53 \mathrm{~min}$
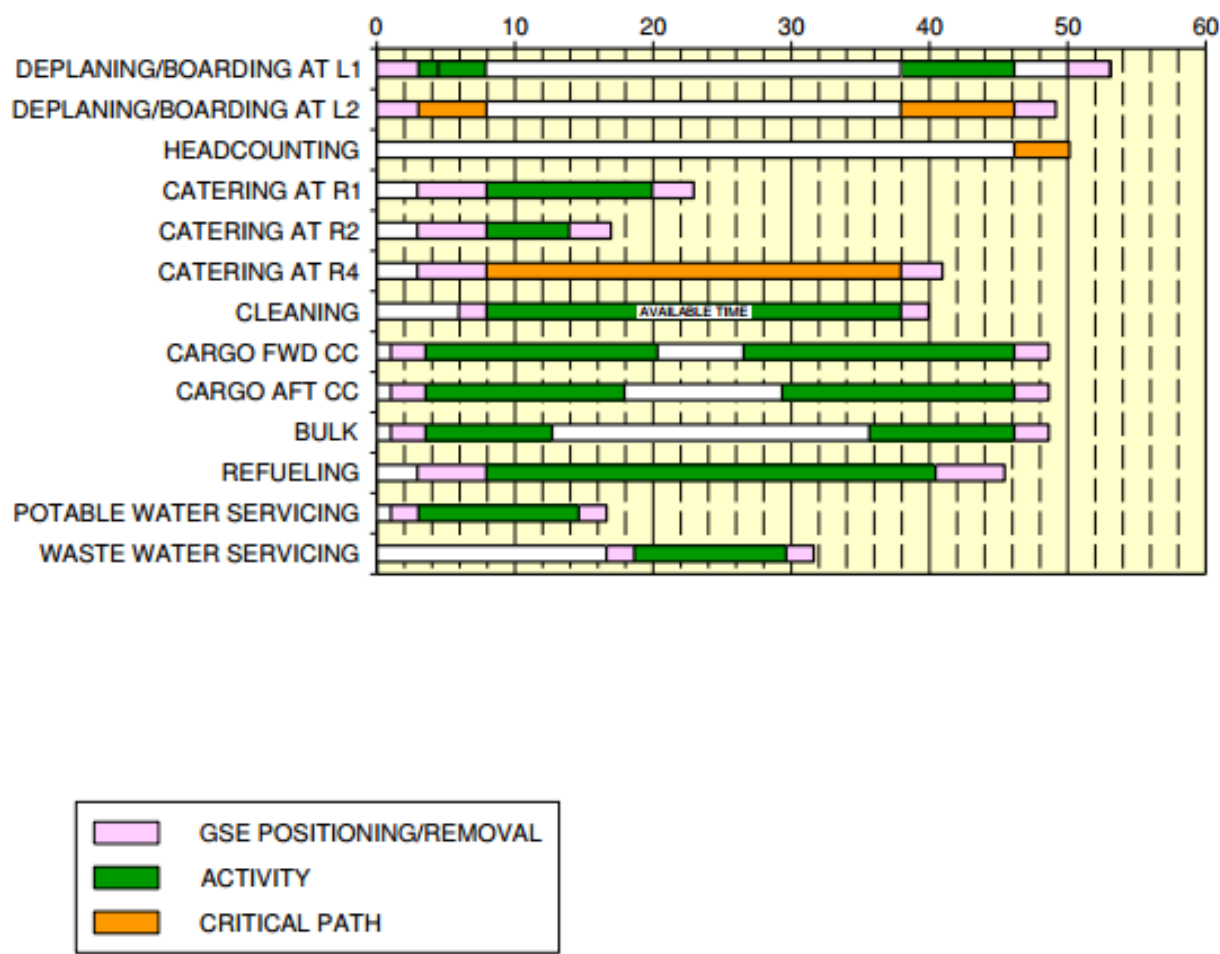

Figure 4: Example of aircraft turnaround time. Source: Airbus A330 AC manual ${ }^{3}$

Further description of the aircraft ground handling and aircraft turnaround process as a whole including the information flows, is publicly available from INTERACTION EU project ${ }^{5}$

The airport infrastructure will be analysed now. In this paper the airport environment will be considered as a linear parking stand layout with two servicing roads at the front and at the back of the aircraft stand. Both servicing roads are connected every 4 to 6 stands (depending on aircraft type as it is wingspan related). See Figure 5

(Note in Europe it is more common to have only a front servicing road front of the aircraft and vehicles can circulate between aircraft stands. In the US it is more frequent to have a service road only at the back with vehicles circulating between aircraft stands as well)

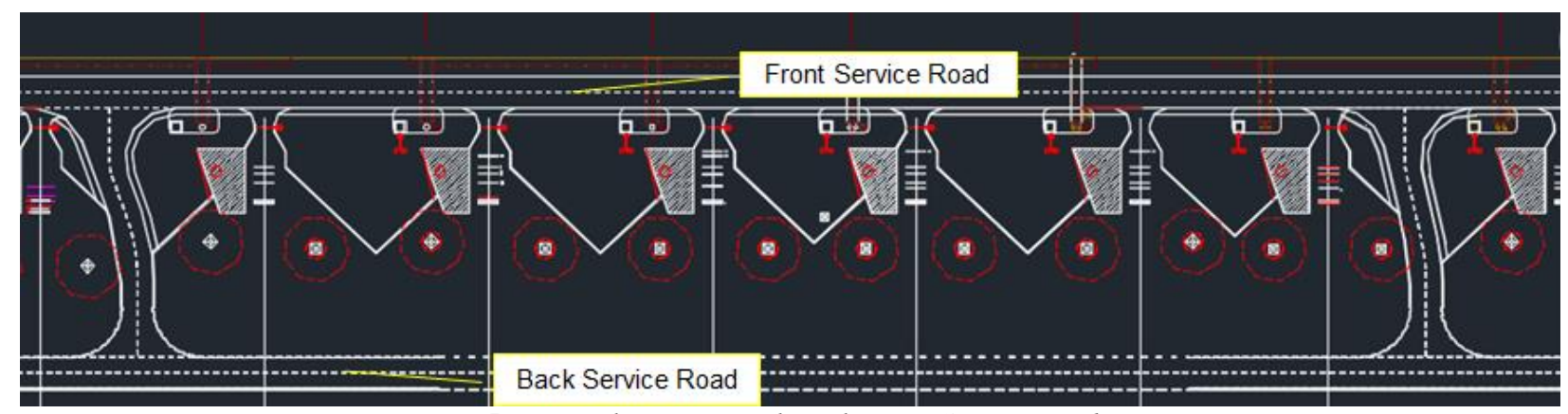

Figure 5: Typical airport parking layout. Source: authors

When GSE are circulating using service roads, the maximum speed allowed will be typically $25 \mathrm{~km} / \mathrm{h}$. When the GSE enters the parking stand, the maximum speed will be $6 \mathrm{~km} / \mathrm{h}^{6}$. For GSE final position to aircraft contact the maximum docking speed will be $0.8 \mathrm{~km} / \mathrm{h}^{6}$. See figure 6 for speed zones 


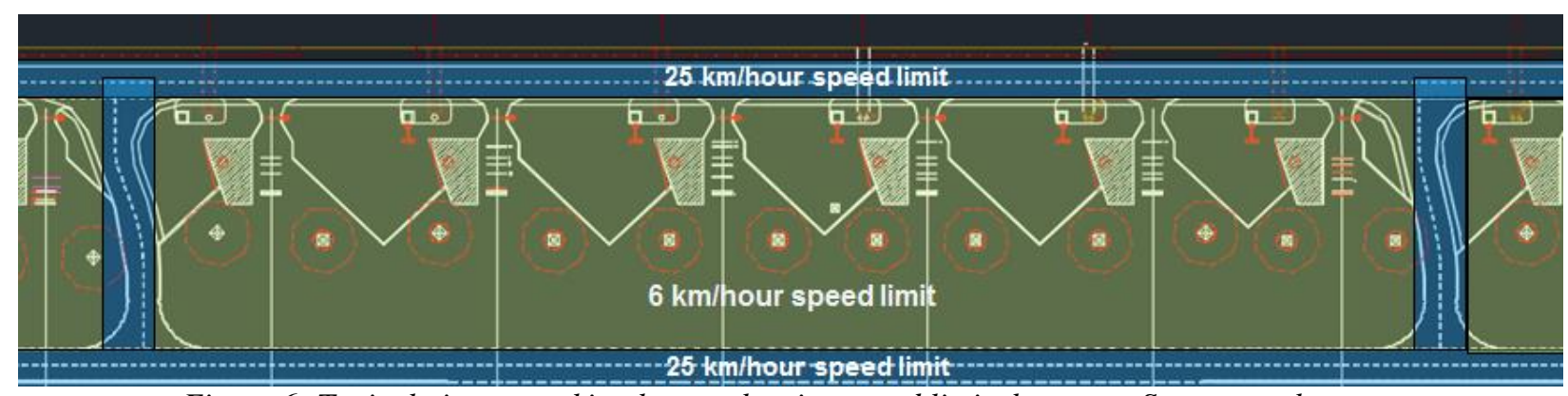

Figure 6: Typical airport parking layout showing speed limits by zones. Source: authors

The number of GSE typically needed for a long range aircraft is presented in Table 1. It is also shown how these resources are usually assigned in the airport environment between aircraft parking stands: linked to parking stand, shared between some stands typically 2 to 4, some zones (e.g. east of passenger terminal) or for the full airport.

\begin{tabular}{|l|l|l|}
\hline Ground Support Equipment (GSE) & Number & Shared Resources Strategy \\
\hline Passenger boarding bridge (PBB) & 1 or 2 & Specific to parking stand \\
\hline Fix GPU attached to PBB & 1 or 2 & Specific to parking stand \\
\hline Fix PCA attached to PBB & 1 or 2 & Specific to parking stand \\
\hline Passenger Stairs & 1 to 2 & Shared with adjacent stands \\
\hline Cargo Loaders & 2 & Shared with adjacent stands/zones \\
\hline Belt loaders & 1 & Shared with adjacent stands/zones \\
\hline Catering trucks & 2 to 3 & Shared with all the airport \\
\hline Cleaning trucks & 0 or 1 & Shared with all the airport \\
\hline Refuelling/hydrant vehicle & 1 & Shared with all the airport \\
\hline GPU mobile & 1 & Shared with adjacent stands/zones \\
\hline PCA mobile & 1 & Shared with adjacent stands/zones \\
\hline Air Start Unit (Engine start) mobile & 0 or 1 & Shared with all the airport \\
\hline Potable water truck & 1 & Shared with all the airport \\
\hline Toilet servicing truck & 1 & Shared with all the airport \\
\hline Towtractor & 1 & Shared with all the airport \\
\hline Baggage tractors & 2 to 3 & Shared with all the airport \\
\hline Container / Pallet dollies & 8 to 26 & Shared with all the airport \\
\hline Bulk dollies & 2 to 3 & Shared with all the airport \\
\hline $\begin{array}{l}\text { Loose and static GSE: cones, chocks, } \\
\text { towbars... }\end{array}$ & Variable & Shared with adjacent stands/zones \\
\hline
\end{tabular}

Table 1: GSE resources for a long range aircraft turnaround time and GSE sharing strategy. Source: authors

On top of all this GSE, there are a number of other vehicles for transport of people (airport staff, airline crew, ground handling crew) that mix and are around the airport stands.

Regarding GSE circulation rules, we will assume:

- Driving on the right lane.

- GSE cannot go under the wing (except for refuelling vehicles) and have to go around the wingtip.

- Any point in the service road can be an entry or exit point to the aircraft parking stands area.

o The front service road for GSE-truck based will be priviledged for access to aircraft most forward door and for the train of dollies. 
- GSE linked to stand or shared between several adjacent stands will depart from and arrive to its parking position in the defined staging area.

- Rest of GSE vehicles will use the back service road from departure and arrival

- For GSE docking or approaching the aircraft, only the toilet servicing vehicle (due to its most frequent typology with the servicing platform at the rear) will use reverse gear.

- For the cargo dolly's train, which is the most complicated trajectory, as a rule it will always leave the aircraft on the left.

With all these assumptions, we can finally plot the traces for GSE trajectories for docking to the aircraft doors and positioning to aircraft servicing panels in Figure 7; and Figure 8 for undocking and exit trajectories. For clarity purposes, only the middle point of the GSE front steering axle path (in red), and the GSE wheel envelope (in green) are plotted. To be noted that both train of dollies are in both sets of trajectories as they each make at least two separate trips to unload the cargo holds and to load it respectively.

The trajectories in the same stand and with the same aircraft type, airline and the same turnaround type will vary largely between turnarounds as they depend on GSE vehicle turning radius and steering characteristics, start position (for parked GSE) the current environment status when GSE actually move and the most important and variable factor: the human driver.

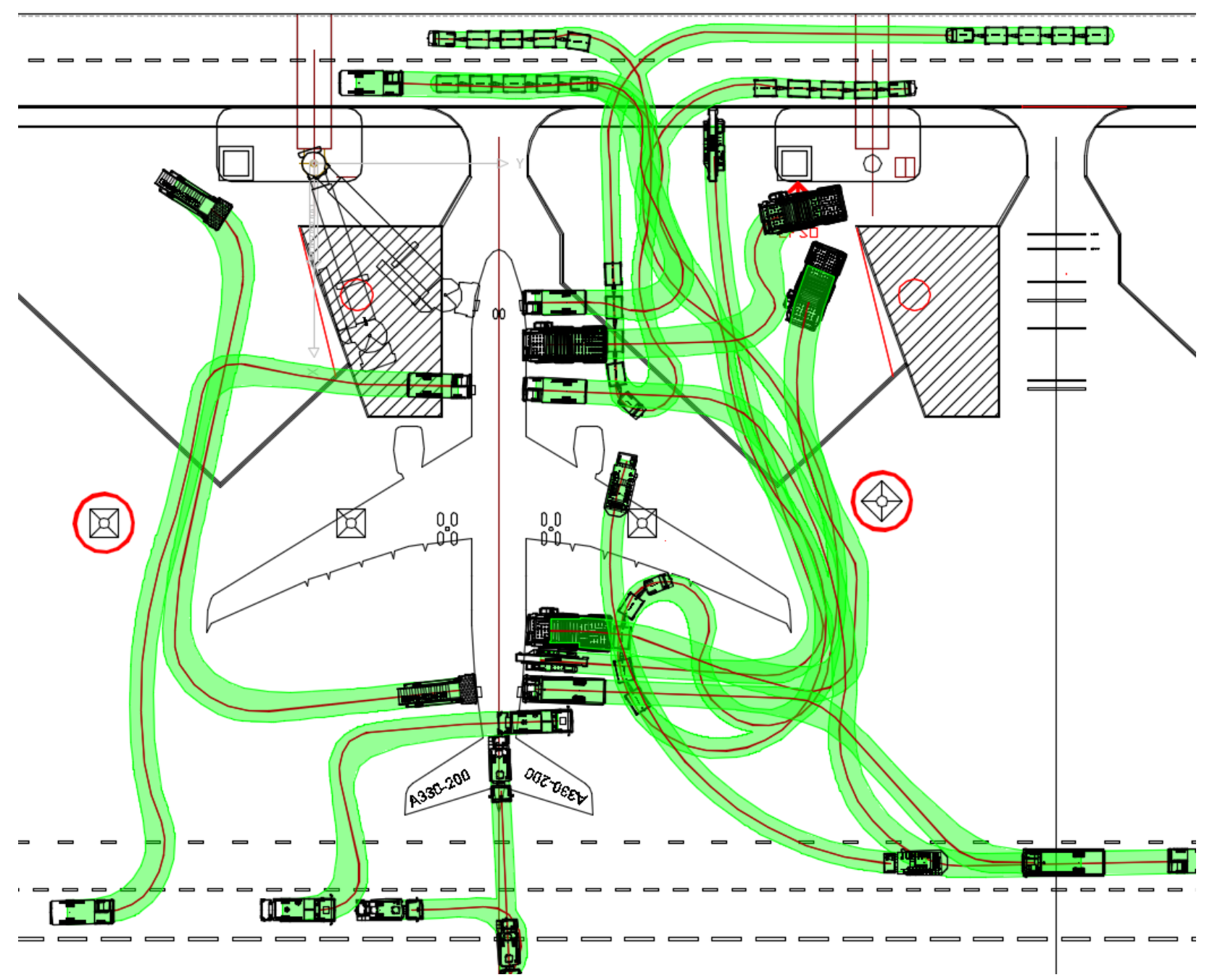

Figure 7: GSE positioning trajectories and wheel envelope to the aircraft. Source: authors simulation 


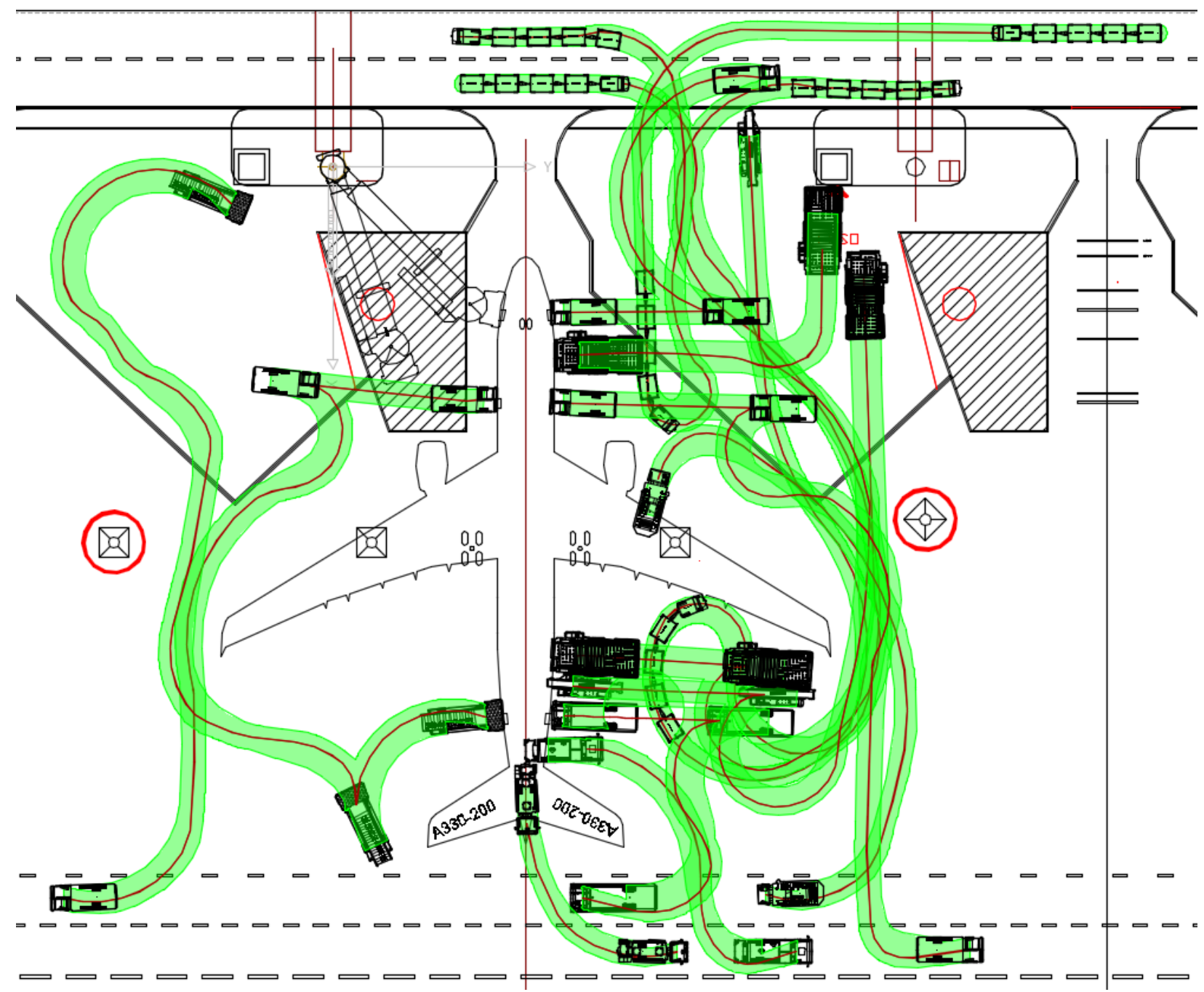

Figure 8: GSE undocking trajectories and wheel envelope to the aircraft. Source: authors simulation

Finally, all the trajectories are plotted in Figure 9, where crossings and common tracks represent potential conflicts areas. In these spots, conflicts are avoided by time separation of vehicles. This can generate traffic congestion when queues build up. 


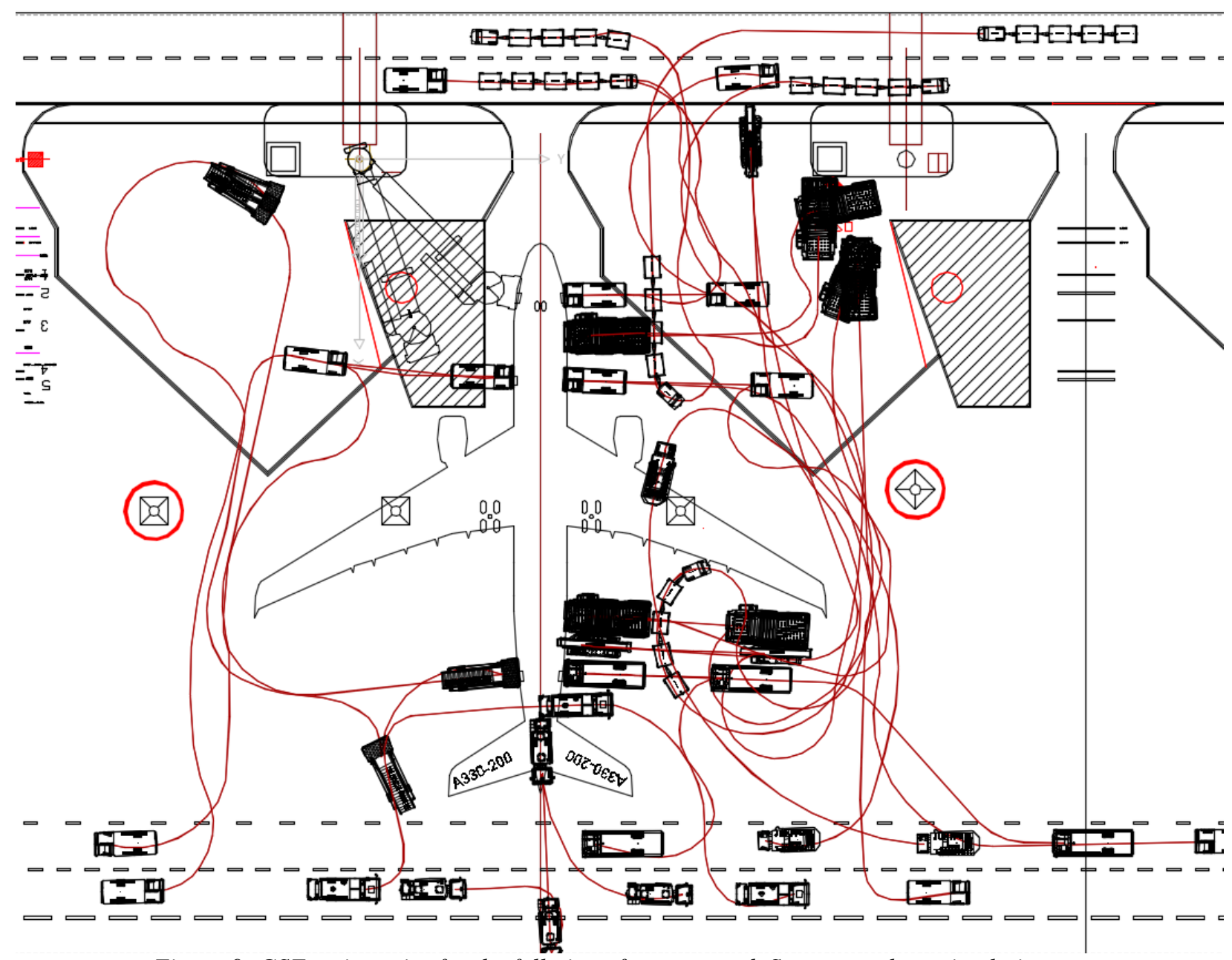

Figure 9: GSE trajectories for the full aircraft turnaround. Source: authors simulation

As per all the above description and using the conclusions of other projects (INTERACTION EU project ${ }^{5}$ ), we can summarize the main inefficiencies related to the aircraft ramp handling as:

- Availability (free and on working state) of airport infrastructure

- Availability (free and on working state) of GSE

- Ramp congestion

- Coordination of actors and resources to perform the tasks

- Aircraft ramp damage

\section{Opportunities for Automation of Ground Handling Systems}

The aircraft handling operation at an airport as described in the previous section details the current situation, but is not significantly different to the way it was $10,20,30$ or even 50 years ago. There have been no major changes in the operation since the beginning of aircraft commercial operation. However, the technology and its cost have evolved tremendously, making possible options that could not be envisaged before.

There are some general favourable conditions or enablers for aircraft ground handling automation:

1) All current and future civil passenger aircraft of more than one hundred seats are very similar from ground handling perspective. For this purpose an aircraft is a fuselage tube with at least two separated decks for passenger cabin and cargo. The fuselage has attached a low wing with positive swept angle where the 2 (or 4) engines are 
hanging; the landing gear has a tricycle configuration with one nose landing gear and 2 (or more) main landing gears.

As an illustration, in Figure 10 is shown a front view comparison of some long range aircraft: A350-900 in yellow, A330-200 in red, 777-300ER in blue, 787-10 in cyan.

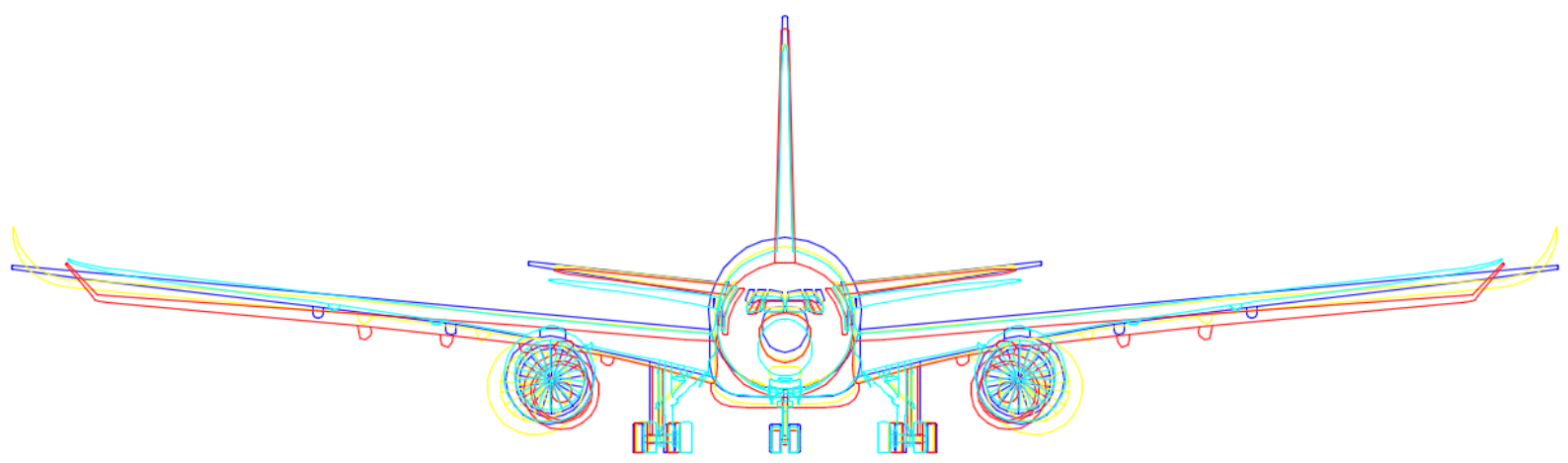

Figure 10:Aircraft comparison. Source: Airbus, Boeing, authors

2) The aircraft doors and its usage are standardized: passenger doors on the forward port side for passenger boarding/deplaning, on the starboard side and aft port side for catering and cleaning activities.

Forward and after the wing, are the cargo doors (available only on the aircraft starboard side) for cargo activities. The bulk door for bulk items only, always the at the aircraft rear part (on short range aircraft always on starboard side; for long range aircraft may be on the port or on starboard side).

3) The aircraft servicing points locations and the aircraft - GSE interface follow standards ${ }^{7,8}$ and are at common areas, see Figure 11: electricity always at the front, fuel under the wing half way to the fuselage (depending on airframers and options on left and/or right hand side) low pressure and high pressure air in front of the wing, potable water (either front or most commonly back in the aircraft) and toilet servicing at the aircraft fuselage end.

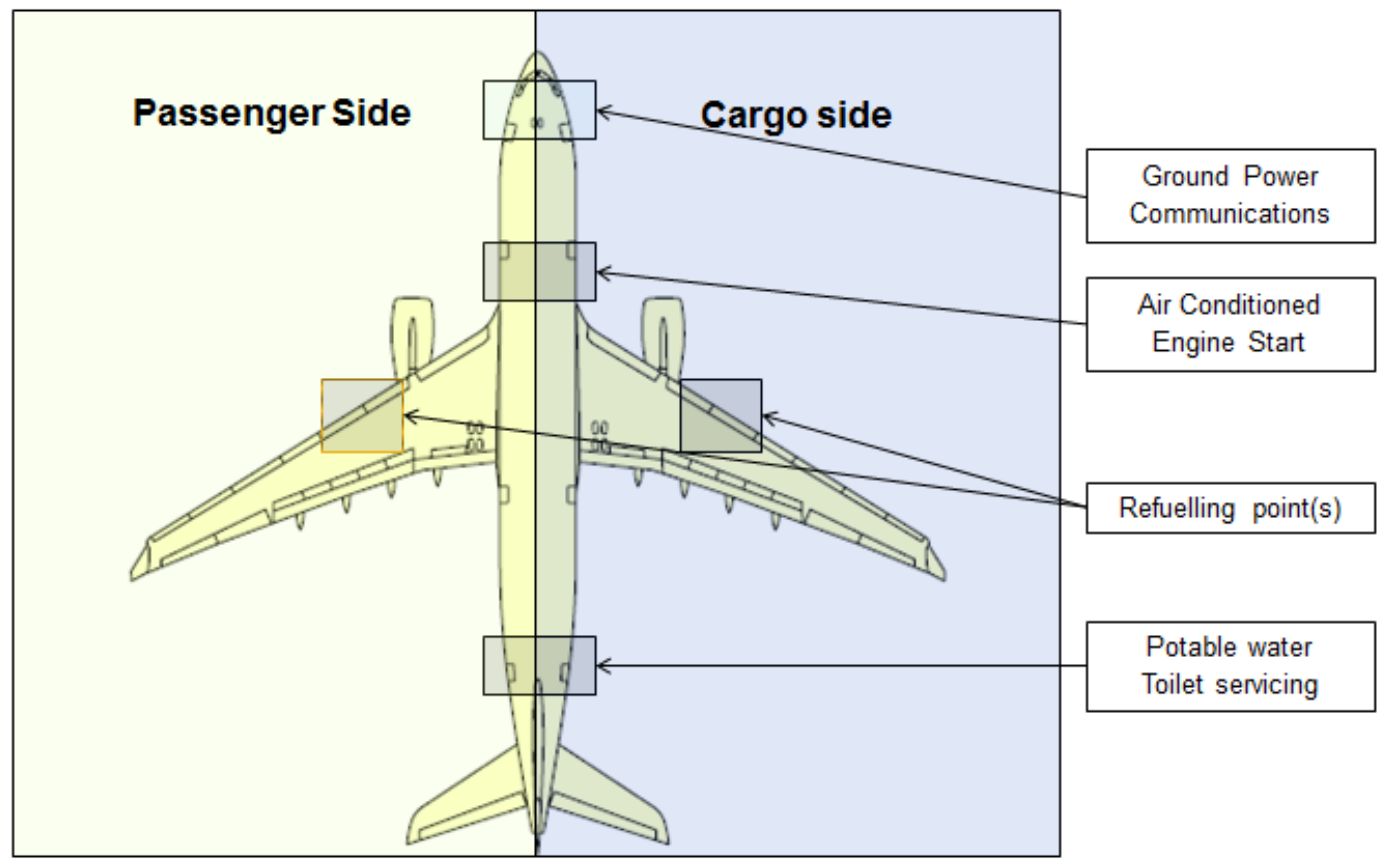

Figure 11: Aircraft servicing points location. Source: Airbus, Boeing, authors 
4) The aircraft couplings for GSE connection are standardized ${ }^{9}$.

5) Robotics and autonomous vehicle technology is available, tested and operated in indoor and outdoor environments. The airport ramp is an outdoor environment, subject to weather conditions, but is also a quite homogeneous and controllable environment, mostly flat (slopes not going typically beyond 3\%) and with a limited number of potential events of known actors and vehicles. Furthermore, the technology now is available and also affordable.

6) Operator ergonomic (health and safety) requirements becoming more stringent. It started with load lifting limits in Scandinavia and is slowly but steadily spreading out.

7) Availability of manpower. In certain cyties where the living expenses are high with low airport ramp wages, finding manpower willing to work on an airport is very difficult.

8) Momentum for automation exists at the airports, mainly for the terminal buildings and related to self-service passengers service (Self-check-in, Baggage drop-off, passport e-gate...). We may see this trend extend it to the airport ramp.

9) Security challenges. The less people around the aircraft, the less potential threats.

10) Airport/Aircraft safety challenges: mainly aircraft ramp damage. A more controlled aircraft environment will help to control the evolution of vehicles around the aircraft and remove the human error factor (e.g. speeding, no respect of procedures) and enforce procedures (e.g. report damage).

As a result, we see that automation can take a bigger role in the aircraft handling environment in:

- Aircraft movement:

- Aircraft last turn into parking stand

$\circ \quad$ Aircraft pushback (e.g. e-taxi ${ }^{10}$ )

$\circ$ Aircraft towing or dispatch towing (e.g. Taxibot ${ }^{11}$ )

- Aircraft ground handling:

$\circ$ Docking of GSE vehicles to aircraft passenger and cargo doors

- Movement of GSE vehicles around the aircraft

- Movement of vehicles on the airport area

The automated supply of utilities to aircraft (electricity, air, water) beyond the conveyance of the servicing unit to the aircraft panel point location is not feasible in the short to mid-term future. Since the aircraft servicing panels (with manual latches) have not been conceived to be opened remotely or operated by a robot in any way. Also, all aircraft couplings or connectors that are standard, cannot be easily connected and disconnected with a simple and affordable robot. Therefore, they will continue to be operated manually in the immediate future.

As solutions exist for aircraft movement ${ }^{10,11}$, the focus of this paper is in the aircraft ground handling part and to the points which are specific to this environment, the docking of GSE vehicles to the aircraft doors and the movement of GSE vehicles around the aircraft.

\section{Challenges and Future for Aircraft Handling Automation}

The main challenges for implementing automation into the aircraft ground handling system can be classified as:

- Aircraft related:

- No palletised cargo hold for many aircraft yet (for some aircraft, e.g. B737 the cargo hold volume is not enough for receiving Unilt Load Devices (ULD) like containers and pallets that can be treated by a conveyance system), making mandatory manual processing.

- Certification rules. Even remote door opening which is perfectly technically feasible as of today and one of the enablers for further automation, is not envisaged in current certification rules. 
- Operational:

- Airport "environment": weather conditions, number of stakeholders with lots of potential conflicts and diverging interests.

- Mix mode: manual and automate mode coexisting on airports. Cannot go to full automation overnight; both will need to co-exist, which is the most complicated environment.

- Government rules, that currently prevent fully automated vehicle on the airport ramp (case of Germany, for example).

- Conservative industry mindset. Systems need to be "bullet-proof" to have the buy-in from the industry with no second opportunities. Failure is not an option.

- Cost and affordability of the solution. No GSE manufacturers research available, only limited - Scientific: development or adaptation are carried out.

- Real time control of heterogeneous fleet of vehicles.

- Use of nonlinear and hybrid control theory to design of $2 \mathrm{D}+\mathrm{T}$ and $3 \mathrm{D}+\mathrm{T}$ ultra-accurate guidance laws for autonomous service vehicles.

- Planning of 2D+T conflict free trajectories between GSE using heuristic and semi-heuristic methods.

- Responsivity to incidents and disruptions.

- Modelling of the ground handling process as a hybrid dynamical system (continuous time-event driven).

- Design of coordination and communication schemes for monitoring the different sub-processes.

- Introduce new hybridization schemes between sensors to improve positioning of GSE.

The set of solutions for the aircraft ground handling automation, on existing aircraft can be:

In the short term:

- Targets around aircraft doors as enabler for assisted and automated docking of GSE to aircraft. See SAE AS $6896^{12}$ and current proposed target in Figure 12 for relative position and distance assessment of GSE to aircraft (the "O" part of the target ), aircraft door identification (the triangles in the corners) and autoleveling function (the " $\mathrm{L}$ " in the top left corner) when GSE is in docked position.

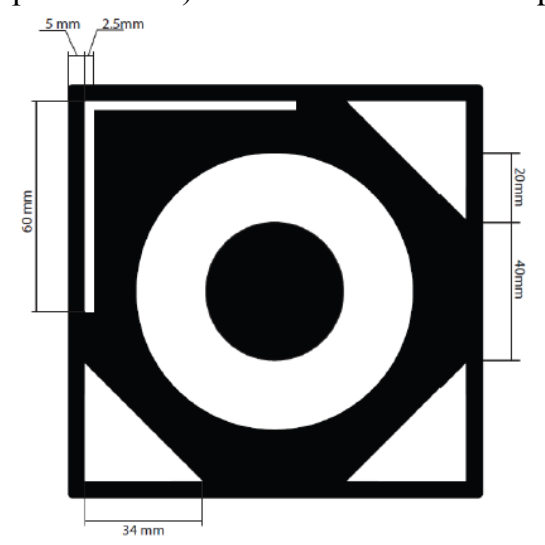

Figure 12: Example aircraft target around doors for GSE docking

In the mid term:

- Robotising of aircraft systems: remote opening of doors and access panels, automatic connection of systems and utilities. (Physical and information exchange).

- Automated cargo loading system within the aircraft.

On the longer term:

- Aircraft cabin supplies changes, easier for automation and servicing, e.g. catering load supplies more modular with full galley exchange instead of individual trolleys. A more modular aircraft cabin concept ${ }^{13}$ could be flyable (a concept that has existed on paper for many years). 
Around the aircraft parking area, in the short-mid term:

A presentation of some elements of a new automated system compared to the current state of the art, would be:

- The same circulation rules and speed applied as explained in section II

- Further to aircraft arrival and with the exact stopped position known the automatic definition of a zoning to be used by the GSE vehicles for their trajectories, see Figure 13:

○ Up-down corridors: Connecting front and back service roads on both sides of the aircraft (shown in blue) and allowing movement in both directions.

- Side corridors (shown in green): Connecting the up-down with the aircraft servicing areas.

- Specific corridor for refuelling vehicles going under the wing that will join the side corridors

As a natural consequence, all GSE vehicles will have straight movement trajectories.

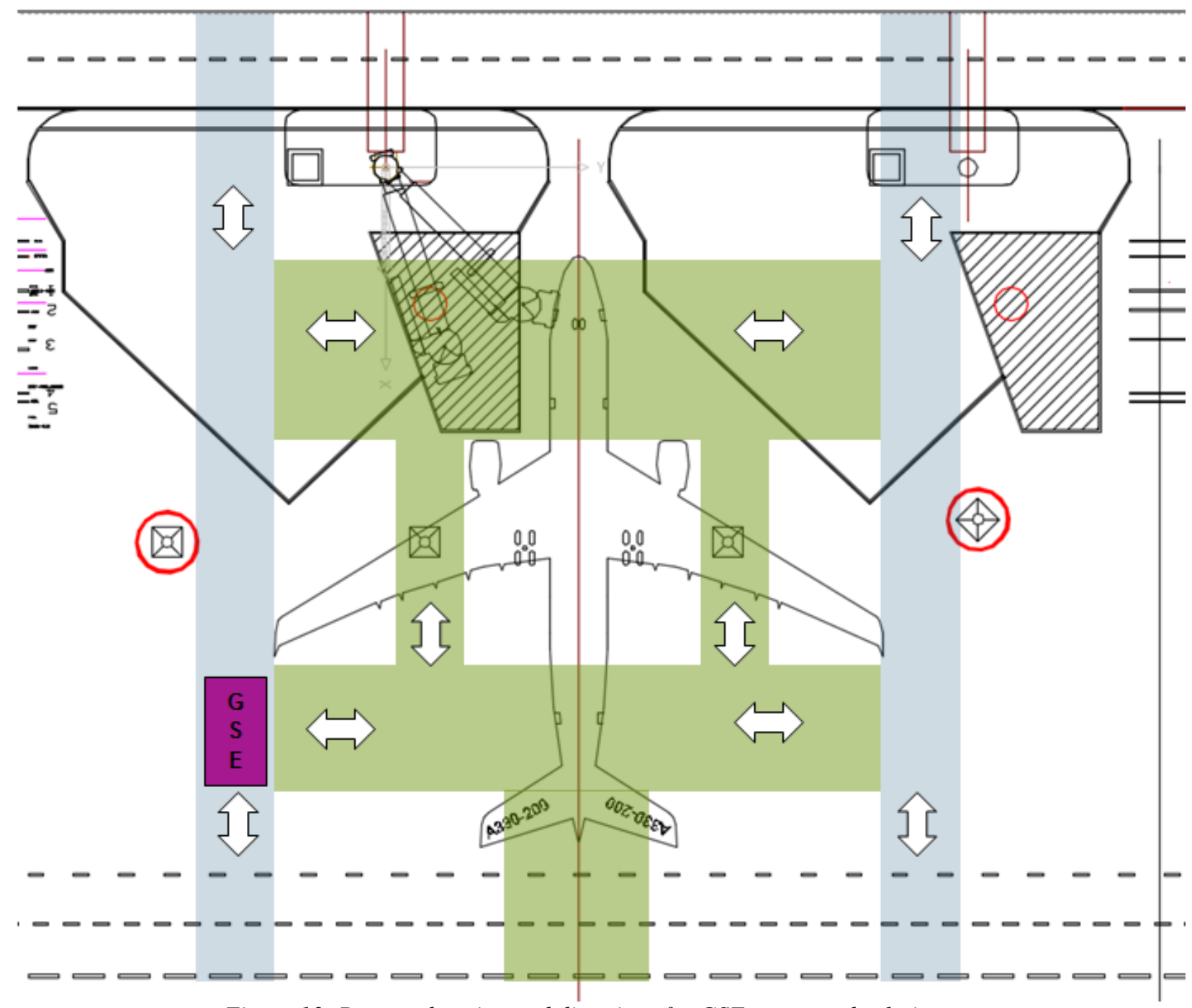

Figure 13: Proposed zoning and directions for GSE automated solution

- To set the priority in case of movement conflict for our case of GSE automated systems, we have used the Table 1 clarifying the priority rules for all GSE involved in the turnaround: 


\begin{tabular}{|l|c|l|l|}
\hline Ground Support Equipment (GSE) & Number & Shared Resources Strategy & $\begin{array}{l}\text { Priority in case of } \\
\text { movement conflict }\end{array}$ \\
\hline Passenger boarding bridge (PBB) & 1 or 2 & Specific to parking stand & 2 \\
\hline Fix GPU attached to PBB & 1 or 2 & Specific to parking stand & N/A \\
\hline Fix PCA attached to PBB & 1 or 2 & Specific to parking stand & N/A \\
\hline Passenger Stairs & 1 to 2 & Shared with adjacent stands & 3 \\
\hline Cargo Loaders & 2 & Shared with adjacent stands/zones & 4 \\
\hline Belt loaders & 1 & Shared with adjacent stands/zones & 7 \\
\hline Catering trucks & 2 to 3 & Shared with all the airport & 5 \\
\hline Cleaning trucks & 0 or 1 & Shared with all the airport & 6 \\
\hline Refuelling/hydrant vehicle & 1 & Shared with all the airport & 1 \\
\hline GPU mobile & 1 & Shared with adjacent stands/zones & 11 \\
\hline PCA mobile & 1 & Shared with adjacent stands/zones & 12 \\
\hline Air Start Unit (Engine start) mobile & 0 or 1 & Shared with all the airport & 16 \\
\hline Potable water truck & 1 & Shared with all the airport & 8 \\
\hline Toilet servicing truck & 1 & Shared with all the airport & 9 \\
\hline Towtractor & 1 & Shared with all the airport & 10 \\
\hline Baggage tractors & 2 to 3 & Shared with all the airport & 13 \\
\hline Container / Pallet dollies & 8 to 26 & Shared with all the airport & 14 \\
\hline Bulk dollies & 2 to 3 & Shared with all the airport & 15 \\
\hline $\begin{array}{l}\text { Loose and static GSE: cones, } \\
\text { chocks, towbars.. }\end{array}$ & Variable & Shared with adjacent stands/zones & N/A \\
\hline Tabl $2: G S E$ resourcs $f \circ a$ & & \\
\hline
\end{tabular}

Table 2: GSE resources for a long range aircraft turnaround time and GSE sharing strategy with priority established. Source: authors

With this proposed solution, the trajectories shown in Figure 9 will be much simplified. Congestion will be managed more easily with the automated GSE system. This idea of simplifying trajectories is not new: for example, for the train of dollies, some operators use transporter vehicles wich conmute between the cargo loader docked in position to the aircraft and the dolly train aligned to the aircraft fuselage beyond the wingtip. These transporters take one ULD at a time from one point to the other. The same modus operandi could be used for an automated system.

Considering that in the near future part of the ground handling activities will remain manually operated, ground handling automation will have to be gradually implemented. The first generation of automated ground handling should be relative to the operation of a fleet of specialized autonomous vehicles. These vehicles will be equipped with sensors useful for:

- navigation in the ground handling area and access paths

- guidance along the service access ways

- collision threat detection with people, other vehicles and fixed obstacles (aircraft and airport installations)

- automated docking to aircraft using visual targets.

Already available four orientable wheel vehicles should allow to follow standard tracks composed of straight lines and sharp turns materialized in the ground handling manoeuvre area allowing lateral and direct approaches to the body of the aircraft. Adoption of electrical propulsion supposes accessibility to electrical stations either to charge an 
on-board battery to replace the used one by a charged one. With the momentum the electrical GSE has nowadays, this can be assumed as granted in the near future.

Each automated vehicle will follow an operations cycle composed of several stages (idle park, maintenance, energy charge, charge/discharge operations at aircraft) taking place at specific locations linked by nominal paths.

The whole ground handling fleet will be managed from an operations centre. This management will be performed in accordance with the Collaborative Decision Making (CDM) scheme adopted in the considered airport. This operations centre will be responsible for:

- Assigning vehicles to specific arrival and departure flights according to availability and proximity.

- Generating a time schedule for each activity performed by the GSEs assigned to each particular ground handling operation. For that, an extension of PERT technique to include as activities the motion of the GSEs within the ground handling area and take into account priority rules between them will allow to establish nominal time tables for each GSEs during its assignment to a given ground handling operation, so that time constraints generated by the airport CDM will be ensured.These nominal timings should correspond to conflict free trajectories for the GSEs.

- On-line follow up of each ground handling operation, however, considering the characteristics of vehicles and planned trajectories, automated conflict resolution schemes, such as those resulting from the edge reversal ${ }^{18}$ technique, could be implemented.

- Management of fleet incidents (vehicle failure) by implementing greedy approaches to restart as soon as possible the corrupted tasks of the ground handling operation.

\section{Conclusion}

The automation of aircraft operations inside the airport parking area will provide opportunities for reducing fuel consumption, reducing cockpit crew workload, improving the predictability of parking and ground handling delays, improving the protection of people, materials and equipment. This new operational concept may lead naturally to the redesign of aircraft ground facilities in terms of layout, interfaces, dimensions and equipment.

More specifically, enabling automated handling of the aircraft as we remove some of the tasks that are currently done by humans would have the following benefits:

- Costs reduction: resource optimization for humans since $80 \%$ of ground handling cost is manpower related.

- Rise of profile for handling staff: from very low-minimum wage profile with high turnover to technical/maintenance people skill profile.

- Get rid of ergonomic constraints in airport GSE (e.g. loading heights).

- Security benefit: the less people around the aircraft the less opportunities for threats.

- Safety benefit: most incidents and accidents are human related. Reduce human induced errors, automate reporting (key point for ground handling damage in composite aircraft)

- Increase awareness of the aircraft status on ground with early detection of performance issues.

- "Industrialisation" of the aircraft operation on ground, improving predictability, with more robust rotations less subject to disruption and less spread in times when aircraft are processed (to be noted, not necessarily further reducing the TRT).

\section{References}

${ }^{1}$ IATA AHM - Aircraft Handling Manual, IATA AHM 810 Standard Ground Handling Agreement

${ }^{2}$ ACDM milestones, mainly the Target Off block time (TOBT) http://www.eurocontrol.int/articles/airport-collaborativedecision-making-cdm

${ }^{3}$ Aircraft Characteristics or Airport Planning Manuals (accessed April 2017):

Airbus: http://www.airbus.com/support/maintenance-engineering/technical-data/aircraft-characteristics/

Boeing: http://www.boeing.com/commercial/airports/plan manuals.page

Bombardier: https://eservices.aero.bombardier.com/wps/portal/eServices/Public/AirportEmergencyPublication

Embraer: http://www.embraercommercialaviation.com/Pages/Apms.aspx

${ }^{4} \mathrm{EU}$ ground handling directive

http://eur-lex.europa.eu/legal-content/EN/ALL/?uri=CELEX\%3A31996L0067

${ }^{5}$ INTERACTION EU FP7 project:

http://www.interaction-aero.eu/Publications/PublicDeliverables.aspx

American Institute of Aeronautics and Astronautics 
D2.1 General Characterisation of Airport Processes and their interactions

D2.3 Identification of Inefficiencies and Needs for Improvement

${ }^{6}$ ISO 6966-2: Aircraft Ground Equipment-Basic Requirements - Part 2: Safety requirements

${ }^{7}$ Aircraft servicing points location:

ISO 10842 - Aircraft Ground service connections - Locations and types. (latest revision from 2006. Currently on revision by document author expected publication in 2017)

SAE ARP 4084B - Aircraft Ground service connections - Locations and type (2012 latest revision by document author)

${ }^{8}$ Aircraft - GSE interface requirements:

ISO 7718-1 Interface requirements in vicinity of passenger doors (main deck doors )

ISO 7718-2 Interface requirements in vicinity of passenger doors (upper deck doors)

${ }^{9}$ Aircraft couplings and interface standards:

ISO 45 - Pressure Refuelling connection

ISO 17775 -- Potable water, toilet flushing and drainage connections

ISO 461-2-- Ground electrical supply connection

SAE AS 4262B and ISO 1034: Ground air conditioning connection

ISO 2026-- Engines air start connection

AS 1614C and ISO 8267-1: Tow bar attachment fittings

${ }^{10} \mathrm{e}$-taxi: http://www.airbus.com/presscentre/pressreleases/press-release-detail/detail/airbus-signs-mou-with-honeywell-andsafran-to-develop-electric-taxiing-solution-for-the-a320-family/

${ }^{11}$ Taxibot: http://www.taxibot-international.com/

${ }^{12}$ SAE AS 6896 - Aircraft Markings for GSE alignment. Draft status. Document sponsor being the paper author. https://www.sae.org/servlets/works/documentHome.do?docID=AS6896\&inputPage=wIpSdOcDeTaIlS\&comtID=TEAAGE3

${ }^{13}$ https://flytranspose.com/

${ }^{14}$ Askin, A.G, Standridge, C.R, "Modeling and Analysis of Manufacturing Systems". John Wiley \& Sons, 1993

${ }^{15}$ Kolisch, R. \& Padman, R, “ An integrated survey of deterministic project scheduling.” Omega, 29, 2001

${ }^{16} \mathrm{Li}$, R. K.-Y., \& Willis, R. J. "Resource constrained scheduling within fixed project durations", The Journal of the Operational Research Society, 44, 1993

${ }^{17} \mathrm{Wu}, \mathrm{N}$ and Zhow, M., "Modeling and deadlock control of automated guided vehicle systems", IEEE/ASME Transactions on Mechatronics, vol 9, 2004.

${ }^{18}$ Lengerke O., González Acuña H., Suell Dutra, M., França F., Mora-Camino. F, "Distributed Control of Job-shop Systems via Edge Reversal Dynamics for Automated Guided Vehicles", IARIA, 2012 